\title{
Níveis de plasma sangüíneo em pó em dietas para leitões desmamados aos 21 dias de idade ${ }^{1}$
}

\author{
Fellipe Freitas Barbosa ${ }^{2}$, Aloízio Soares Ferreira ${ }^{3}$, Gustavo Gattás ${ }^{2}$, Francisco Carlos de \\ Oliveira Silva ${ }^{4}$, Juarez Lopes Donzele ${ }^{3}$, Paulo César Brustolini ${ }^{3}$, Darci Clementino Lopes ${ }^{3}$
}

1 Projeto financiado pela FAPEMIG e pelo CNPq.

2 Zootecnista.

${ }^{3}$ Departamento de Zootecnia, Universidade Federal de Viçosa - Viçosa - MG, CEP: 36571-000.

${ }^{4}$ EPAMIG/CTZM, Viçosa - MG, CEP: 36571-000.

RESUMO - Objetivando-se avaliar níveis de inclusão de plasma sangüíneo em pó nas dietas para leitões desmamados aos 21 dias de idade, foram utilizados 112 animais com peso inicial de 5,90 \pm 0,40 kg distribuídos em delineamento experimental de blocos ao acaso com quatro tratamentos e sete repetições com quatro animais por unidade experimental, em três períodos subseqüentes: 21 aos 28 dias (período 1), 29 aos 35 dias (período 2) e 36 aos 42 dias (período 3). Os leitões foram mantidos no experimento dos 43 aos 56 dias (período 4) recebendo dieta convencional de creche. Os tratamentos consistiram de níveis de inclusão de 0,$0 ; 4,0 ; 6,0$ e 8,0\% de plasma sangüíneo em pó no período $1 ; 0,0 ; 2,8 ; 4,2$ e 5,6\% no período 2 e 0,$0 ; 2,0 ; 3,0$ e 4,0\% no período 3. O ganho de peso médio diário (GPMD) aumentou de forma quadrática até os níveis estimados de 4,3; 2,5 e $1,3 \%$ de inclusão de plasma sangüíneo em pó na dieta, nos períodos 1,2 e 3 , respectivamente. Não se observou efeito significativo da inclusão de plasma sangüíneo em pó sobre o consumo de ração diário médio e GPMD no período 4. Concluiu-se que os níveis de inclusão de plasma sangüíneo em pó nas dietas para leitões desmamados aos 21 dias de idade são de $4,3 \%$ na primeira semana, $2,5 \%$ na segunda e de $1,3 \%$ na terceira semana pós-desmame.

Palavras-chave: alimento alternativo, fase inicial, manejo alimentar, pós-desmame

\section{Spray dry blood plasma levels in diets for piglets weaned at 21 days of age}

\begin{abstract}
With the objective to evaluate the inclusion of spray dry blood plasma in diets for piglets weaned at 21 days of age $(5.9 \pm 0.40 \mathrm{~kg}$ initial BW), a total of 112 animals were allotted to completely randomize block design with four treatment and seven replications with four animals per experimental unit, in three subsequent periods: from 21 to 28 days (period 1), from 29 to 35 days (period 2), from 36 to 42 days (period 3). The piglets were maintained in the experiment from 43 to 56 days (period 4) fed conventional nurse diet. The treatments consisted of inclusion levels of $0.0,4.0,6.0$, and $8.0 \%$ of spray dry blood plasma in the period $1,0.0 ; 2.8 ; 4.2$ and $5.6 \%$ in the period 2 and $0.0 ; 2.0 ; 3.0$ and $4.0 \%$ in the period 3 . The average daily weight gain (ADWG) increased in a quadratic form up to the estimate inclusion levels of 4.3, 2.5 and 1.3 of spray dry blood plasma in the diet, in the periods 1, 2 and 3, respectively. No significant effect was observed for the inclusion levels of spray dry blood plasma on daily feed intake and ADWG in the period 4. The inclusion levels of spray dry blood plasma in diets for pigs weaned at 21 days of age should be 4.3 for the first week, 2.5 for the second and $1.3 \%$ for the third week post weaning.
\end{abstract}

Key Words: alternative feedstuff, feeding management, post weaning, initial phase

\section{Introdução}

A prática do desmame precoce tem sido utilizada na produção como forma de melhorar a produtividade na suinocultura brasileira. Suinocultores têm substituído o desmame tradicional por desmames em idades iguais ou inferiores a 21 dias de idade. Essa prática foi implementada visando aumentar os índices produtivos da granja, como número de partos/porca/ano e número de desmamados/porca/ano.

No entanto, até os 28 dias de idade, o sistema digestório dos leitões não produz quantidades suficientes de amilases, lipases e outras enzimas responsáveis pela digestão dos nutrientes de matérias-primas de origem vegetal usadas em dietas para a fase pré-inicial. Dependendo dos substratos utilizados nas dietas, o desenvolvimento do sistema enzimático do leitão se completa até a oitava semana de idade.

O desmame, além de ocasionar estresse ao animal, em decorrência da mudança de ambiente e da separação da mãe, impõe aos leitões mudança brusca na alimentação, uma vez que a dieta constituída basicamente de leite materno é substituída por outra à base de ingredientes de origem vegetal. 
Neste contexto, para o sucesso da utilização de desmames precoces, os nutricionistas devem atentar-se especialmente à formulação de dietas, que devem ser preparadas de modo a apresentar melhor digestibilidade, palatabilidade e eficiência econômica (Chae et al., 1999).

Tem se observado que o consumo de ração pelos leitões nos primeiros dias pós-desmame tem sido baixo, provavelmente, em razão do estresse decorrente da separação da mãe, da formação de novo lote de animais e das mudanças de alimentação líquida de alta digestibilidade para a sólida de menor digestibilidade. Por isso, o fornecimento de dietas com ingredientes de melhor digestibilidade pode tornar-se necessário para o crescimento adequado nas primeiras semanas após o desmame. A utilização de dietas complexas formuladas com fontes protéicas de origem animal e vegetal tem sido estudada na expectativa de que essa mistura tenha efeito associativo e possa melhorar a digestibilidade dos nutrientes das dietas (Ferreira et al., 2001; Teixeira et al., 2003).

Diversos alimentos alternativos têm sido avaliados no intuito de melhorar o desempenho dos animais nas primeiras semanas pós-desmame. O plasma sangüíneo em pó pode ser uma fonte efetiva de proteína animal, por aumentar o consumo de ração e o ganho de peso pósdesmame (Ermer et al., 1992; Hansen et al., 1993; Touchette et al., 2002; Lawrence et al., 2004), diminuir a incidência de diarréia pós-desmame (Russel et al., 1996; Harrell et al., 2000; Owusu-Asiedu et al., 2002) e possuir efeito protetor ao intestino delgado (Torrallardona et al., 2003).

Face ao exposto, verifica-se a necessidade de determinar os níveis de inclusão de plasma sangüíneo em pó em dietas pré-iniciais complexas em diferentes períodos sobre o desempenho de leitões desmamados aos 21 dias de idade.

\section{Material e Métodos}

O experimento foi conduzido no Setor de Suinocultura do Departamento de Zootecnia do Centro de Ciências Agrárias da Universidade Federal de Viçosa, em ViçosaMG, no período de novembro de 2004 a fevereiro de 2005.

Foram utilizados 112 leitões mestiços (Landrace $\times$ Large White $\times$ Duroc), 56 machos castrados e 56 fêmeas (com peso inicial de 5,90 $\pm 0,40 \mathrm{~kg}$ ), distribuídos em delineamento de blocos ao acaso, com quatro tratamentos, sete repetições e quatro animais por unidade experimental (dois machos e duas fêmeas).

Os tratamentos utilizados consistiram da inclusão de quatro níveis de plasma sangüíneo em pó, de forma decres- cente em função da idade. No período 1 (dos 21 aos 28 dias), foram utilizados os níveis de $0 ; 4,0 ; 6,0$ e 8,0\% de inclusão de plasma sangüíneo em pó; no período 2 (dos 29 aos 35 dias), níveis de $0 ; 2,8 ; 4,2$ e 5,6\%; no período 3 (dos 36 aos 42 dias), níveis de $0 ; 2,0 ; 3,0$ e 4,0\%; e no período 4 os animais receberam a mesma dieta inicial.

Aos 21 dias de idade, os animais foram desmamados, pesados e transferidos para a creche, onde foram alojados em gaiolas metálicas $(1,60 \mathrm{~m}$ de comprimento $\times 1,0 \mathrm{~m}$ de largura) suspensas a $0,56 \mathrm{~m}$ do chão, com piso e laterais telados, dotadas de comedouros semi-automáticos e bebedouros tipo chupeta, localizadas em um prédio de alvenaria com piso de concreto e forro de madeira rebaixado. O aquecimento do ambiente foi feito por meio de lâmpadas incandescentes.

Durante 21 dias pós-desmame, foram misturadas as dietas experimentais, formuladas para que o consumo mínimo de plasma sang üíneo em pó se mantivesse em 0 ; $10 ; 14$ e $18 \mathrm{~g} / \mathrm{animal} /$ dia durante o período experimental. Na formulação, utilizou-se plasma sang üín eo em pó misto (de origens bovina e suína), obtido pela separação das frações plasma e células do sangue, via centrifugação e posterior secagem pelo processo de spray-dried.

As dietas experimentais (fareladas, isoenergéticas e isoprotéicas) foram formuladas à base de milho e farelo de soja e suplementadas com minerais e vitaminas, segundo recomendações contidas em Rostagno et al. (2000), mantendo-se a relação aminoacídica entre lisina e os demais aminoácidos essenciais, exceto metionina + cistina, treonina e triptofano, com base na proteína ideal para suínos na fase pré-inicial. O nível de lactose também foi mantido constante nos diferentes tratamentos dentro de cada período. As composições centesimais e calculadas das dietas experimentais relativas aos períodos 1, 2 e 3 são apresentadas nas Tabelas 1, 2 e 3.

Dos 42 aos 56 dias de idade (período 4), os animais foram alimentados com a mesma dieta inicial à base de milho e farelo de soja, com $18,0 \%$ de PB, $0,95 \%$ de lisina, $3.400 \mathrm{kcal}$ $\mathrm{de} \mathrm{ED} / \mathrm{kg}$, formulada para atender às recomendações descritas por Rostagno et al. (2000).

As dietas e a água foram fornecidas à vontade aos animais avaliados. Os animais foram pesados semanalmente (aos 28, 35 e 42 dias de idade) e ao final do período experimental (56 dias de idade). As sobras de ração foram coletadas diariamente, pesadas semanalmente e diminuídas das quantidades fornecidas para estimativa do consumo da unidade experimental.

A temperatura ambiente foi registrada por meio de termômetros de máxima e mínima e de bulbo seco e bulbo 
Tabela 1 - Composições centesimal e calculada das dietas experimentais fornecidas no período 1 ( 21 a 28 dias de idade)

Table 1 - Percentage and calculated compositions of the experimental diets fed in the period 1 (from 21 to 28 day old)

\begin{tabular}{|c|c|c|c|c|}
\hline \multirow[t]{2}{*}{$\begin{array}{l}\text { Ingrediente (\%) } \\
\text { Ingredient }\end{array}$} & \multicolumn{4}{|c|}{$\begin{array}{c}\text { Nível de plasma em pó (\%) } \\
\text { Spray dried plasma level }\end{array}$} \\
\hline & 0 & 4,00 & 6,00 & 8,00 \\
\hline Milho (Corn) & 44,195 & 46,094 & 47,096 & 47,995 \\
\hline Farelo de soja (Soybean meal) & 27,000 & 27,000 & 27,000 & 27,000 \\
\hline Plasma(Spray dried plasma) & - & 4,00 & 6,00 & 8,00 \\
\hline Leite em pó (Integral dried milk) & 15,000 & 8,000 & 4,000 & - \\
\hline Lactose & 3,300 & 6,500 & 8,500 & 10,500 \\
\hline Óleo de soja (Soybean oil) & 3,000 & 2,310 & 2,110 & 2,100 \\
\hline Amido (Starch) & 2,550 & 1,500 & 0,940 & 0,000 \\
\hline Inerte (Inert) & 1,070 & 0,590 & 0,350 & 0,370 \\
\hline Fosfato bicálcico & 1,860 & 2,000 & 2,100 & 2,230 \\
\hline \multicolumn{5}{|l|}{ Dicalcium phosphate } \\
\hline Calcário (Limestone) & 0,700 & 0,700 & 0,700 & 0,700 \\
\hline Sal (Salt) & 0,400 & 0,200 & 0,150 & 0,100 \\
\hline Óxido de zinco (Zinc oxide) & 0,318 & 0,318 & 0,318 & 0,318 \\
\hline Suplemento vitamínico ${ }^{1}$ & 0,150 & 0,150 & 0,150 & 0,150 \\
\hline $\begin{array}{l}\text { Vitamin mix } \\
\text { Suplemento mineral }\end{array}$ & 0,100 & 0,100 & 0,100 & 0,100 \\
\hline $\begin{array}{l}\text { Mineral mix } \\
\text { Colistina } \\
\text { Colistine }\end{array}$ & 0,010 & 0,010 & 0,010 & 0,010 \\
\hline BHT & 0,020 & 0,020 & 0,020 & 0,020 \\
\hline L-lisina $\mathrm{HCl}$ & 0,108 & 0,200 & 0,182 & 0,167 \\
\hline L-lysine & & & & \\
\hline DL-metionina (99\%) & 0,110 & 0,160 & 0,150 & 0,130 \\
\hline DL-methionine & & & & \\
\hline L-treonina (L-threonine) & 0,090 & 0,140 & 0,120 & 0,110 \\
\hline L-triptofano (L-tryptophan) & 0,020 & 0,008 & 0,004 & - \\
\hline \multicolumn{5}{|l|}{$\begin{array}{l}\text { Composição calculada } \\
\text { Calculated composition }\end{array}$} \\
\hline $\mathrm{PB}(C P)(\%)$ & 21,1 & 21,8 & 22,0 & 22,2 \\
\hline $\mathrm{ED}(D E)(\mathrm{kcal} / \mathrm{kg})$ & 3.530 & 3.510 & 3.506 & 3.511 \\
\hline $\mathrm{Ca}(\%)$ & 1,009 & 0,969 & 0,950 & 0,939 \\
\hline $\mathrm{P}$ total $(\%)$ & 0,750 & 0,733 & 0,725 & 0,722 \\
\hline $\begin{array}{l}\text { Total P } \\
\text { P disponível (\%) }\end{array}$ & 0,572 & 0,551 & 0,542 & 0,538 \\
\hline $\begin{array}{l}\text { Available } P \\
\text { Relação Ca:P total } \\
\text { Ca:P ratio }\end{array}$ & 1,34 & 1,32 & 1,31 & 1,30 \\
\hline $\begin{array}{l}\text { Lisina total }(\%) \\
\text { Total lysine }\end{array}$ & 1,374 & 1,536 & 1,538 & 1,544 \\
\hline Lisina digestível (\%) & 1,233 & 1,399 & 1,405 & 1,411 \\
\hline $\begin{array}{l}\text { Digestible lysine } \\
\text { Met+Cis digestível (\%) } \\
\text { Digestible methionine plus cystine }\end{array}$ & 0,740 & 0,840 & 0,850 & 0,849 \\
\hline Metionina digestível (\%) & 0,465 & 0,506 & 0,489 & 0,461 \\
\hline $\begin{array}{l}\text { Digestible methionine } \\
\text { Treonina digestível (\%) }\end{array}$ & 0,910 & 0,929 & 0,928 & 0,936 \\
\hline $\begin{array}{l}\text { Digestible threonine } \\
\text { Triptofano digestível (\%) }\end{array}$ & 0,262 & 0,265 & 0,266 & 0,267 \\
\hline Digestible tryptophan & & & & \\
\hline Lactose $(\%)$ & 10,70 & 10,35 & 10,32 & 10,29 \\
\hline Relação met:lis digestíveis & 0,60 & 0,60 & 0,60 & 0,60 \\
\hline
\end{tabular}

${ }^{1}$ Conteúdo por kg (amount/kg): $12.000 \mathrm{UI}$ de vit. A; 2.250 UI de vit. $\mathrm{D}_{3} ; 27 \mathrm{mg}$ de vit. E; $3 \mathrm{mg}$ de vit. K; $2,25 \mathrm{mg}$ de tiamina (thiamin); $6 \mathrm{mg}$ de riboflavina (riboflavin); $2,25 \mathrm{mg}$ de piridoxina (piridoxine); $27 \mathrm{mcg}$ de vit. $\mathrm{B}_{12} ; 400 \mathrm{mcg}$ de ácido fólico (folic acid; $150 \mathrm{mcg}$ de biotina (biotin); $22,5 \mathrm{mcg}$ de ácido pantotênico (pantothenic acid); $45 \mathrm{mg}$ de niacina (niacin); $300 \mathrm{mcg}$ de Se.

2 Conteúdo por $\mathrm{kg}$ (amount/kg): $88 \mathrm{mg}$ de Fe; $15 \mathrm{mg}$ de $\mathrm{Cu} ; 80 \mathrm{mg}$ de $\mathrm{Zn}$; $45 \mathrm{mg}$ de $\mathrm{Mn} ; 1 \mathrm{mg}$ de I.
Tabela 2 - Composições centesimal e calculada das dietas experimentais fornecidas no período 2 ( 29 a 35 dias de idade)

Table 2 - Percentage and calculated compositions of the experimental diets fed in the period 2 (29 from 35 day old)

\begin{tabular}{|c|c|c|c|c|}
\hline \multirow[t]{2}{*}{ Ingrediente $(\%)$} & \multicolumn{4}{|c|}{$\begin{array}{c}\text { Nível de plasma em pó }(\%) \\
\text { Spray dried plasma level }\end{array}$} \\
\hline & 0 & 2,80 & 4,2 & 5,6 \\
\hline Milho (Corn) & 49,785 & 50,259 & 50,678 & 51,691 \\
\hline Farelo de soja (Soybean meal) & 29,000 & 29,000 & 29,000 & 29,000 \\
\hline Plasma (Spray dried plasma) & - & 2,800 & 4,200 & 5,600 \\
\hline Leite em pó (Integral dried milk) & 11,200 & 5,600 & 2,800 & - \\
\hline Lactose & 3,100 & 5,370 & 6,510 & 7,650 \\
\hline Óleo de soja (Soybean oil) & 2,960 & 2,870 & 2,640 & 1,810 \\
\hline Fosfato bicálcico & 1,670 & 1,920 & 2,060 & 2,200 \\
\hline \multicolumn{5}{|l|}{ Dicalcium phosphate } \\
\hline Calcário (Limestone) & 0,650 & 0,650 & 0,650 & 0,650 \\
\hline Sal $($ Salt $)$ & 0,400 & 0,350 & 0,300 & 0,250 \\
\hline Óxido de zinco & 0,318 & 0,3180 & 0,318 & 0,3180 \\
\hline $\begin{array}{l}\text { Zinc oxide } \\
\text { Suplemento vitamínico }\end{array}$ & 0,150 & 0,150 & 0,150 & 0,150 \\
\hline $\begin{array}{l}\text { Vitamin mix } \\
\text { Suplemento mineral } \\
\text { Mineral mix }\end{array}$ & 0,100 & 0,100 & 0,100 & 0,100 \\
\hline Colistina & 0,010 & 0,010 & 0,010 & 0,010 \\
\hline $\begin{array}{l}\text { Colistine } \\
\text { BHT }\end{array}$ & 0,020 & 0,020 & 0,020 & 0,020 \\
\hline $\begin{array}{l}\text { L.lisina } \mathrm{HCl} \\
\text { L.lysine }\end{array}$ & 0,260 & 0,244 & 0,244 & 0,246 \\
\hline DL-metionina $(99 \%)$ & 0,194 & 0,178 & 0,169 & 0,161 \\
\hline \multicolumn{5}{|l|}{ DL-methionine } \\
\hline \multicolumn{5}{|l|}{ L-threonine } \\
\hline L-triptofano & 0,013 & 0,008 & 0,004 & - \\
\hline
\end{tabular}

L-tryptophan

Composição calculada

Calculated composition

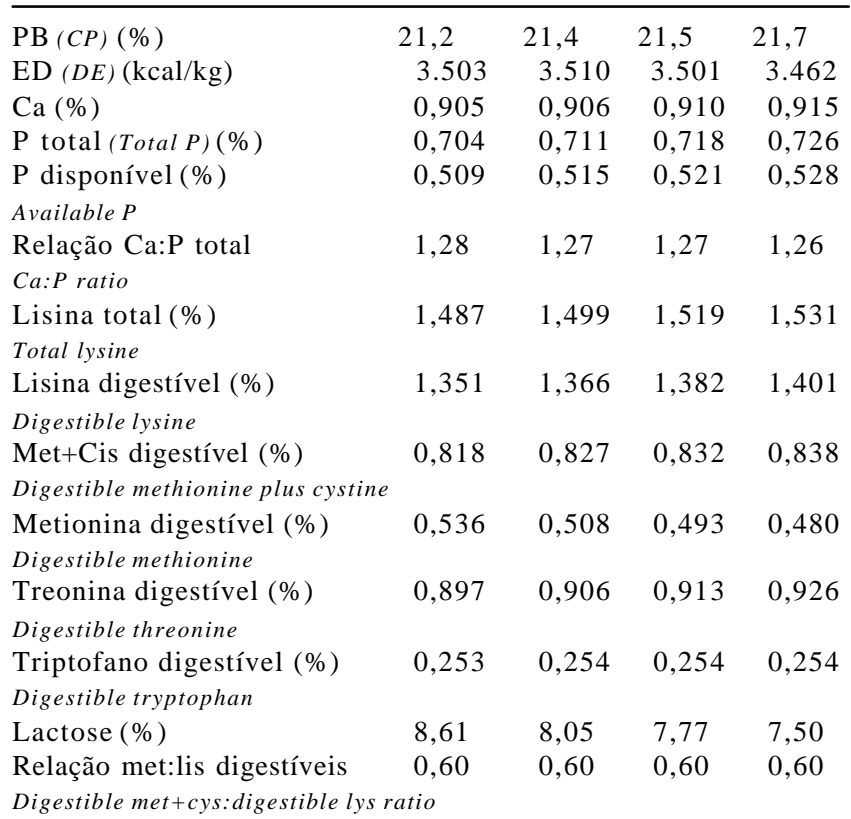

${ }^{1}$ Conteúdo por kg (amount/kg): $12.000 \mathrm{UI}$ de vit. A; 2.250 UI de vit. $\mathrm{D}_{3} ; 27 \mathrm{mg}$ de vit. E; $3 \mathrm{mg}$ de vit. $\mathrm{K} ; 2,25 \mathrm{mg}$ de tiamina (thiamin); $6 \mathrm{mg}$ de riboflavina (riboflavin); 2,25 mg de piridoxina (piridoxine); $27 \mathrm{mcg}$ de vit. $\mathrm{B}_{12} ; 400 \mathrm{mcg}$ de ácido fólico (folic acid; $150 \mathrm{mcg}$ de biotina (biotin); $22,5 \mathrm{mcg}$ de ácido pantotênico (pantothenic acid); $45 \mathrm{mg}$ de niacina (niacin); $300 \mathrm{mcg}$ de Se.

2 Conteúdo por $\mathrm{kg}$ (amount/kg): $88 \mathrm{mg}$ de $\mathrm{Fe} ; 15 \mathrm{mg}$ de $\mathrm{Cu} ; 80 \mathrm{mg}$ de $\mathrm{Zn}$; $45 \mathrm{mg}$ de $\mathrm{Mn} ; 1 \mathrm{mg}$ de I. 
Tabela 3 - Composições centesimal e calculada das dietas experimentais fornecidas no período 3 ( 36 a 42 dias de idade)

Table 3 - Percentage and calculated compositions of the experimental diets fed in the period 3 (36 from 42 day of age)

\begin{tabular}{|c|c|c|c|c|}
\hline \multirow[t]{2}{*}{$\begin{array}{l}\text { Ingrediente }(\%) \\
\text { Ingredient }\end{array}$} & \multicolumn{4}{|c|}{$\begin{array}{c}\text { Nível de plasma em pó }(\%) \\
\text { Spray dried plasma level }\end{array}$} \\
\hline & 0 & 2,00 & 3,00 & 4,00 \\
\hline Milho(Corn) & 52,475 & 52,677 & 52,702 & 52,950 \\
\hline Farelo de soja (Soybean meal) & 30,700 & 30,700 & 30,700 & 30,700 \\
\hline Plasma (Spray dried plasma) & - & 2,000 & 3,000 & 4,000 \\
\hline Leite em pó (Integral dried milk) & 8,000 & 4,000 & 2,000 & - \\
\hline Lactose & 1,850 & 3,500 & 4,350 & 5,100 \\
\hline Óleo de soja (Soybean oil) & 2,880 & 2,950 & 3,000 & 3,030 \\
\hline Fosfato bicálcico & 1,800 & 1,950 & 2,000 & 2,100 \\
\hline \multicolumn{5}{|l|}{ Dicalcium phosphate } \\
\hline Calcário (Limestone) & 0,650 & 0,660 & 0,680 & 0,670 \\
\hline Sal (Salt) & 0,400 & 0,300 & 0,250 & 0,200 \\
\hline Óxido de zinco (Zinc oxide) & 0,318 & 0,318 & 0,318 & 0,318 \\
\hline Suplemento vitamínico ${ }^{1}$ & 0,150 & 0,150 & 0,150 & 0,150 \\
\hline \multicolumn{5}{|l|}{ Vitamin mix } \\
\hline $\begin{array}{l}\text { Suplemento mineral } \\
\text { Mineral mix }\end{array}$ & 0,100 & 0,100 & 0,100 & 0,100 \\
\hline Colistina & 0,010 & 0,010 & 0,010 & 0,010 \\
\hline \multicolumn{5}{|l|}{ Colistine } \\
\hline BHT & 0,020 & 0,020 & 0,020 & 0,020 \\
\hline L-lisina $\mathrm{HCl}$ & 0,280 & 0,290 & 0,300 & 0,287 \\
\hline \multicolumn{5}{|l|}{ L-lysine } \\
\hline DL-metionina (99\%) & 0,190 & 0,190 & 0,200 & 0,190 \\
\hline \multicolumn{5}{|l|}{ DL-methionine } \\
\hline Treonina digestível (\%) & 0,170 & 0,180 & 0,180 & 0,175 \\
\hline \multicolumn{5}{|l|}{ Digestible threonine } \\
\hline Triptofano digestível (\%) & 0,007 & 0,005 & 0,004 & - \\
\hline Digestible tryptophan & & & & \\
\hline
\end{tabular}

Composição calculada

Calculated composition

\begin{tabular}{|c|c|c|c|c|}
\hline $\mathrm{PB}(C P)(\%)$ & 21,2 & 21,3 & 21,4 & 21,5 \\
\hline $\mathrm{ED}(D E)(\mathrm{kcal} / \mathrm{kg})$ & 3.487 & 3.500 & 3.500 & 3.505 \\
\hline Cálcio (Calcium) (\%) & 0,906 & 0,903 & 0,901 & 0,900 \\
\hline Fósforo total (\%) & 0,715 & 0,715 & 0,710 & 0,716 \\
\hline $\begin{array}{l}\text { Total phosphorus } \\
\text { Fósforo disponível (\%) }\end{array}$ & 0,508 & 0,508 & 0,503 & 0,507 \\
\hline $\begin{array}{l}\text { Available phosphorus } \\
\text { Relação Ca:P total } \\
\text { Ca:P ratio }\end{array}$ & 1,26 & 1,26 & 1,26 & 1,26 \\
\hline $\begin{array}{l}\text { Lisina total }(\%) \\
\text { Total lysine }\end{array}$ & 1,480 & 1,510 & 1,527 & 1,521 \\
\hline Lisina digestível (\%) & 1,338 & 1,37 & 1,391 & 1,390 \\
\hline $\begin{array}{l}\text { Digestible lysine } \\
\text { Met+cis digestível (\%) }\end{array}$ & 0,810 & 0,823 & 0,842 & 0,840 \\
\hline Digestible methionine plus cystin & & & & \\
\hline $\begin{array}{l}\text { Metionina digestível (\%) } \\
\text { Digestible methionine }\end{array}$ & 0,520 & 0,511 & 0,516 & 0,502 \\
\hline Treonina digestível (\%) & 0,884 & 0,910 & 0,919 & 0,923 \\
\hline $\begin{array}{l}\text { Digestible threonine } \\
\text { Triptofano digestível (\%) }\end{array}$ & 0,244 & 0,247 & 0,249 & 0,247 \\
\hline Digestible tryptophan & & & & \\
\hline Lactose $(\%)$ & 5,80 & 5,42 & 5,26 & 5,00 \\
\hline Relação met:lis digestíveis & 0,60 & 0,60 & 0,60 & 0,60 \\
\hline
\end{tabular}

Digestible met + cys:digestible lys ratio

Contendo por kg (Amount/kg): 12.000 UI de vit. A; 2.250 UI de vit. $\mathrm{D}_{3} ; 27 \mathrm{mg}$ de vit. $\mathrm{E} ; 3 \mathrm{mg}$ de vit. $\mathrm{K} ; 2,25 \mathrm{mg}$ de tiamina (thiamin); $6 \mathrm{mg}$ de riboflavina (riboflavin); $2,25 \mathrm{mg}$ de piridoxina (piridoxine); $27 \mathrm{mcg}$ de vit. $\mathrm{B}_{12} ; 400 \mathrm{mcg}$ de ácido fólico (folic acid); $150 \mathrm{mcg}$ de biotina (biotin); $22,5 \mathrm{mg}$ de ácido pantotênico (pantothenic acid); $45 \mathrm{mg}$ de niacina (niacin); $300 \mathrm{mcg}$ de Se.

${ }^{2}$ Conteúdo por $\mathrm{kg}$ (amount $/ \mathrm{kg}$ ): $88 \mathrm{mg}$ de $\mathrm{Fe} ; 15 \mathrm{mg} \mathrm{de} \mathrm{Cu} ; 80 \mathrm{mg}$ de $\mathrm{Zn}$; $45 \mathrm{mg}$ de $\mathrm{Mn} ; 1 \mathrm{mg}$ de I. úmido colocados em uma gaiola localizada na parte mediana do galpão. O registro das temperaturas máxima e mínima foi feito diariamente às $7 \mathrm{~h}$, enquanto que o registro de umidade foi realizado em dias alternados no período compreendido entre 7 e $17 \mathrm{~h}$, em intervalo de duas horas e meia.

Avaliaram-se o ganho de peso, o consumo de ração e o peso final dos animais nos períodos de 21 a 28, 29 a 35, 36 a 42 e 43 a 56 dias de idade utilizando-se análises de variância e regressão. A conversão alimentar não foi analisada estatisticamente, pois os dados não apresentaram distribuição normal.

A análise estatística dos parâmetros estudados foi realizada pelo programa SAEG - Sistema de Análises Estatísticas e Genéticas, versão 7.1 (UFV, 1997).

\section{Resultados e Discussão}

A temperatura no interior das salas de creche durante o período experimental manteve-se entre $24,0 \pm 0,92^{\circ} \mathrm{C}$ (mínima) e $27,2 \pm 1,69^{\circ} \mathrm{C}$ (máxima). A temperatura de bulbo seco registrada foi de $25,4 \pm 1,61^{\circ} \mathrm{C}$ e a umidade relativa média, de $80,0 \pm 7,06 \%$. O índice de temperatura e umidade (ITU) calculado foi de 75,4 $\pm 1,87$, valor próximo da faixa de temperatura ideal para leitões pós-desmame, que, segundo Oliveira et al. (1993), deve ficar em torno de $24^{\circ} \mathrm{C}$.

O peso médio inicial (PI) e o peso médio final (PF) dos animais e os resultados do consumo diário de ração (CDR), do ganho de peso médio diário (GPMD), do consumo diário de plasma (CDP) e da conversão alimentar (CA) dos leitões alimentados com dietas contendo diferentes níveis de plasma sangüíneo em pó nos períodos 1 , 2 e 3 e os resultados relativos ao período 4 são apresentados na Tabela 4.

Não se observou diferença $(P \geq 0,10)$ entre os tratamentos em relação ao CRMD dos animais durante o Período 1 (21 aos 28 dias de idade). Notaram-se baixos níveis de consumo em todos os tratamentos. O consumo de plasma foi inferior ao mínimo estabelecido quando da formulação das dietas. Esse baixo consumo pode ser atribuído ao estresse decorrente da separação da porca e da mudança da alimentação líquida de alta digestibilidade para a sólida de menor digestibilidade e a adaptações fisiológicas e digestivas ao novo sistema de alimentação (Mascarenhas et al., 1999).

Apesar de o CDR não ter variado significativamente entre os tratamentos, os animais alimentados com as dietas com 4,0 e $6,0 \%$ de plasma apresentaram aumento de 4,6 e $7,2 \%$, respectivamente, no consumo em relação àqueles alimentados com a dieta controle. Os animais alimentados 
Tabela 4 - Peso inicial, peso final, consumo de ração, ganho de peso diário, consumo de plasma em pó e conversão alimentar de leitões desmamados aos 21 dias de idade nos períodos 1, 2, 3 e 4

Table 4 - Initial and final body weigh, feed intake, average weight gain, spray dried plasma intake and feed:gain ratio of piglets weaned at 21 days of age in the periods 1, 2, 3 and 4

\begin{tabular}{|c|c|c|c|c|c|c|}
\hline \multirow[t]{2}{*}{ Item $^{1}$} & \multicolumn{4}{|c|}{$\begin{array}{l}\text { Nível de plasma em pó (\%) } \\
\text { Spray dried plasma level }\end{array}$} & \multirow[t]{2}{*}{$\mathrm{P}$} & \multirow[t]{2}{*}{$\begin{array}{l}\mathrm{CV} \\
(\%)\end{array}$} \\
\hline & 0,0 & 4,00 & 6,00 & 8,00 & & \\
\hline Peso inicial ( $\mathrm{kg})$ (Initial body weight, $\mathrm{kg}$ ) & 5,97 & 5,96 & 5,85 & 5,83 & - & - \\
\hline Peso final (kg) (Final body weight, $\mathrm{kg}$ ) & 6,69 & 6,88 & 6,84 & 6,59 & - & - \\
\hline Consumo de ração (g/dia) (Feed intake, g/day) & 181 & 189 & 194 & 161 & ns & 26,81 \\
\hline Ganho de peso diário (g/dia) $)^{2}$ (Daily weight gain, g/day) & 103 & 132 & 140 & 108 & 0,10 & 37,03 \\
\hline Consumo de plasma (g/dia)(Plasma intake, g/day) & 0,00 & 7,60 & 11,65 & 12,90 & - & - \\
\hline Conversão alimentar $(\mathrm{g} / \mathrm{g})$ (Feed:gain ratio, $g / g$ ) & 1,84 & 1,59 & 1,56 & 1,68 & - & - \\
\hline \multirow{3}{*}{$\begin{array}{l}\text { Período } 2^{1} \\
\text { Period } 2\end{array}$} & \multirow{2}{*}{\multicolumn{4}{|c|}{$\begin{array}{c}\text { Nível de plasma em pó (\%) } \\
\text { Spray dried plasma level }\end{array}$}} & \multirow[t]{3}{*}{$\mathrm{P}$} & \multirow{3}{*}{$\begin{array}{l}\mathrm{CV} \\
(\%)\end{array}$} \\
\hline & & & & & & \\
\hline & 0 & 2,8 & 4,2 & 5,6 & & \\
\hline Peso final (kg) (Final body weight, $\mathrm{kg}$ ) & 8,76 & 9,28 & 9,09 & 8,44 & - & - \\
\hline Consumo de ração (g/dia) (Feed intake, g/day) & 376 & 377 & 362 & 336 & $\mathrm{~ns}$ & 18,88 \\
\hline Ganho de peso diário (g/dia) $)^{2}$ (Daily weight gain, g/day) & 296 & 343 & 322 & 264 & 0,05 & 21,22 \\
\hline Consumo de plasma (g/dia) (Plasma intake, g/day) & 0,00 & 10,55 & 15,20 & 18,82 & - & - \\
\hline Conversão alimentar (g/g) (Feed: gain ratio, g/g) & 1,30 & 1,14 & 1,13 & 1,30 & - & - \\
\hline \multirow{3}{*}{$\begin{array}{l}\text { Período } 3^{1} \\
\text { Period } 3\end{array}$} & \multirow{2}{*}{\multicolumn{4}{|c|}{$\begin{array}{l}\text { Nível de plasma em pó (\%) } \\
\text { Spray dried plasma level }\end{array}$}} & \multirow[t]{3}{*}{$\mathrm{P}<$} & \multirow{3}{*}{$\begin{array}{l}\mathrm{CV} \\
(\%)\end{array}$} \\
\hline & & & & & & \\
\hline & 0 & 2,0 & 3,0 & 4,0 & & \\
\hline Peso final $(\mathrm{kg})$ (Final body weight, $\mathrm{kg}$ ) & 11,402 & 12,095 & 11,553 & 10,497 & - & - \\
\hline Consumo de ração (g/dia) (Feed intake, g/day) & 539 & 581 & 518 & 463 & ns & 15,45 \\
\hline Ganho de peso diário (g/dia) (Daily weight gain,g/day) & 377 & 401 & 352 & 294 & 0,10 & 15,85 \\
\hline Consumo de plasma (g/dia) (Plasma intake, g/day) & 0,00 & 11,62 & 15,54 & 18,52 & - & - \\
\hline Conversão alimentar (g/g) (Feed: gain ratio, g/g) & 1,42 & 1,46 & 1,49 & 1,63 & - & - \\
\hline Período $4^{2}$ & \multirow{2}{*}{\multicolumn{4}{|c|}{$\begin{array}{l}\text { Ração inicial } \\
\text { Initial diet }\end{array}$}} & & \\
\hline Period 4 & & & & & & \\
\hline Peso final (kg) (Final body weight, $k g$ ) & 18,167 & 19,099 & 18,284 & 16,618 & - & - \\
\hline Consumo de ração (g/dia) (Feed intake, g/day) & 808 & 829 & 810 & 749 & ns & 9,51 \\
\hline Ganho de peso diário $(\mathrm{g} / \mathrm{dia})^{2}$ (Daily weight gain, g/day) & 483 & 500 & 481 & 466 & $\mathrm{~ns}$ & 12,75 \\
\hline Conversão alimentar (g/g) (Feed:gain ratio, $g / g$ ) & 1,69 & 1,65 & 1,68 & 1,61 & - & - \\
\hline
\end{tabular}

${ }_{1}$ Período 1 - 21 a 28 dias de idade; período 2 - 29 a 35 dias de idade; período 3 - 36 a 42 dias de vida; período 4 - 43 a 56 dias de idade;

1 Period 1 - 21 to 28 days old; period 2- 29 to 35 days old; period 3- 36 to 42 days old; period 4 - 43 to 56 days old.

2 Efeito quadrático(Quadratic effect).

com a dieta com $8,0 \%$ de plasma apresentaram redução de $11,0 \%$ no CDR em comparação aos alimentados com a dieta controle (sem plasma) e de $17,0 \%$ em relação aos alimentados com dietas contendo $6,0 \%$ de plasma. Uma provável piora na palatabilidade da dieta quando os níveis de plasma são superiores a $6 \%$ pode justificar a redução no CDR.

Resultados diferentes foram obtidos por Butolo et al. (1999), ao avaliarem quatro níveis de inclusão de plasma suíno desidratado nas dietas $(0 ; 2,5 ; 5,0$ e 7,5\%), e por Grinstead et al. (2000), que, em experimento com animais desmamados aos $19 \pm 1$ dias de idade, avaliaram a inclusão de dois níveis de plasma sangüíneo em pó nas dietas (2,5 e $5,0 \%)$ e verificaram que o CDR aumentou de forma linear com os níveis de plasma sang uiíneo na dieta.

$O$ ganho de peso aumentou $(\mathrm{P} \leq 0,10)$ de forma quadrática com a adição de plasma sangüíneo em pó nas dietas (Figura 1A), estimando-se em 4,3\% o melhor nível de plasma sangüíneo em pó desidratado em dietas de leitões no período 1. Efeitos positivos da adição de plasma sobre o GPMD dos leitões pós-desmame também foram verificados por Hansen et al. (1993), que relacionaram essa melhora ao maior consumo de ração.

Avaliando cinco fontes de proteína para leitões desmamados, Chae et al. (1999) verificaram maior GPMD durante a primeira semana pós-desmame nos animais alimentados com dietas contendo 9,4\% de plasma sangüíneo em pó. Diversos autores (Ermer et al., 1992; Hansen et al., 1993; Ermer et al., 1994; Pierce et al., 2005) atribuíram a melhora no desempenho dos animais durante esse período ao maior consumo de alimento. Grinstead et al. (2000), avaliando a inclusão de dois níveis de inclusão dietética de plasma sangüíneo em pó $(2,5$ e 5,0\%) na dieta, verificaram aumento linear no GPMD. 

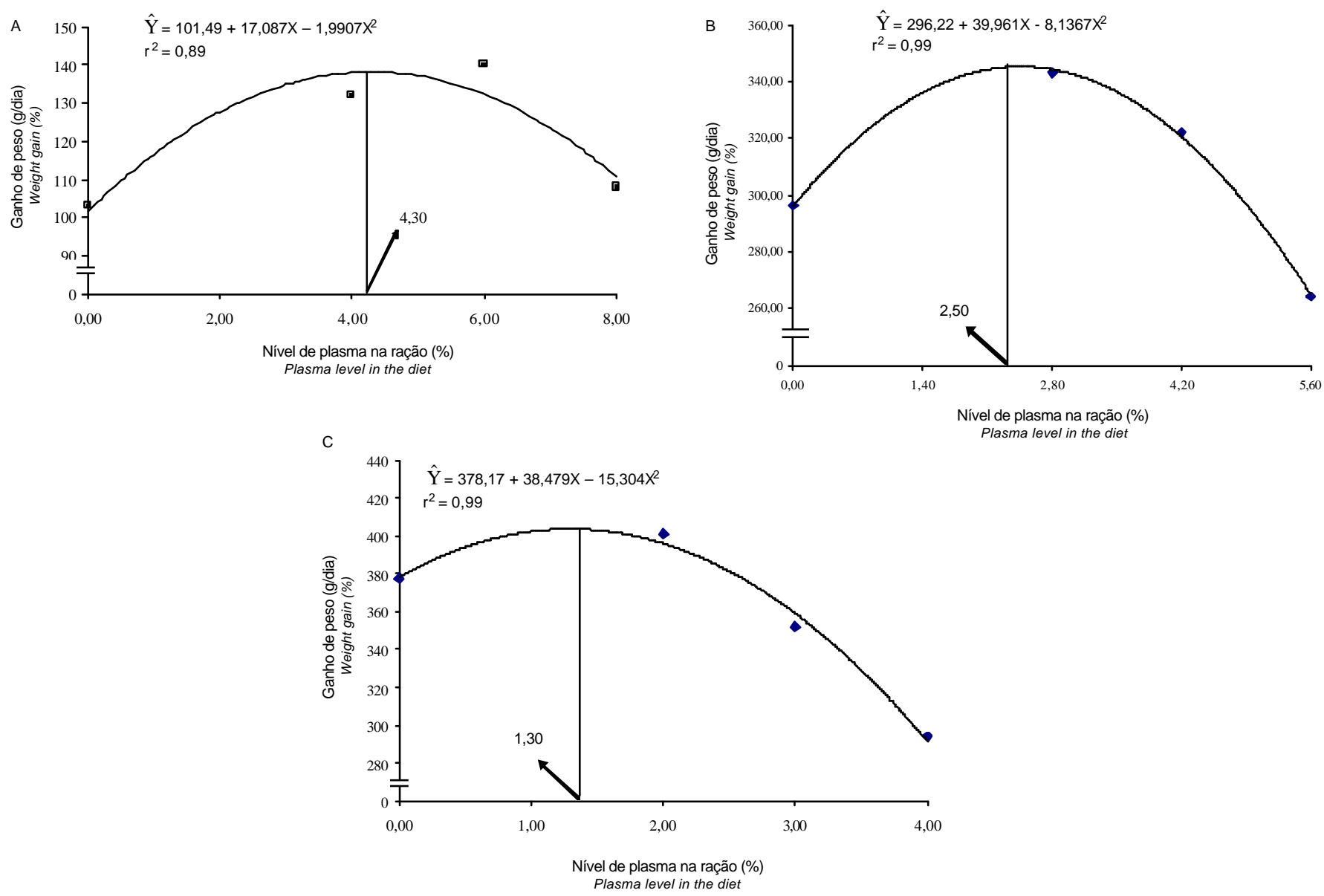

Figura 1 - Representação gráfica do ganho de peso médio diário de leitões alimentados com dietas pré-iniciais com diferentes níveis de plasma em pó, nos períodos 1(A), 2 (B) e 3(C).

Figure 1 - Graphic representation of average daily weight gain of piglets fed pre initial diets with different spray dried plasma levels, periods $1(A), 2(B)$ and $3(C)$.

Goodband et al. (1995) e Shurson et al. (1995) recomendaram a inclusão de 5,0 a 8,0\% de plasma na dieta dos leitões durante uma semana após o desmame, enquanto Kats et al. (2001) observaram que o nível ótimo de inclusão do plasma animal às dietas foi de $6,0 \%$, superior ao encontrado neste trabalho $(4,3 \%)$.

A proteína do plasma é rica em lisina, triptofano e treonina, no entanto, deficiente em isoleucina e, principalmente, metionina. Segundo o NRC (1998), a metionina se torna o primeiro aminoácido limitante em dietas com quantidades superiores a $6,0 \%$ de plasma sangüíneo em pó. Assim, respostas positivas no desempenho dos animais foram obtidas com altos níveis de plasma quando quantidade suficiente de metionina sintética foi adicionada às dietas (Owen et al., 1993; Kats et al., 1994b; Chae et al., 1999). Neste contexto, vários autores estabeleceram em 6,0 a $8,5 \%$ o limite de plasma sangüíneo em pó em dietas pós-desmame sem a suplementação de metionina (Gatnau \& Zimmerman, 1991a; Gatnau et al., 1993; Kats et al., 1994b; Russel \& Weaver, 1996). Dritz et al. (1993), em experimento com 290 leitões, avaliaram a inclusão de metionina em dietas com 5,0 ou $15,0 \%$ de plasma e com relação metionina:lisina menor que a estabelecida pelo NRC (1998) e observaram efeito linear da adição de metionina sobre o ganho de peso e o consumo de alimentos dos animais. Neste experimento, todas as dietas foram formuladas de modo que a relação aminoacídica se mantivesse dentro dos níveis recomendados por Rostagno et al. (2000), o que pode ter favorecido a melhora no desempenho obtida com o nível de até $4,3 \%$ de plasma.

Por outro lado, Butolo et al. (1999), ao avaliarem a inclusão de quatro níveis de plasma suíno desidratado nas dietas $(0,0 ; 2,5 ; 5,0$ e 7,5\%), verificaram que o GPMD não foi influenciado pelas dietas.

A melhora no ganho de peso dos animais pode ser atribuída à diminuição dos efeitos negativos causados pelo estresse pós-desmame por meio da redução dos danos ao intestino delgado e da incidência de diarréia, fatores críticos ao bom desempenho dos leitões (Harrell et al., 2000). É provável que, em decorrência das imunoglobulinas ativas, 
o plasma forneça alguma imunidade local no trato gastrintestinal do leitão na primeira semana pós-desmame (Gatnau \& Zimmerman, 1991b; Nofrarías et al., 2006). Coffey \& Cromwell (1995) também relacionaram as imunoglobulinas presentes no plasma à melhora no desempenho dos animais após o desmame, visto que essas imunoglobulinas podem prevenir os danos causados por patógenos à parede intestinal mantendo as características digestivas e absortivas do intestino. Além disso, Nofrarías et al. (2006) sugeriram menor ativação do sistema imune em leitões alimentados com dietas contendo plasma.

Deprez et al. (1996) e Nollet et al. (1999) justificaram ainda a utilização de plasma sangüíneo em pó pela capacidade de suas glicoproteínas reduzirem a adesão de E. coli aos enterócitos. Esses autores observaram diminuição no número de E.coli nas fezes de suínos alimentados com dietas contendo plasma animal diante de uma infecção induzida.

Os efeitos positivos do plasma sang üíneo em pó são mais perceptíveis quando os animais são submetidos a desafio, a condições adversas de manejo, ou seja, maior resposta produtiva pode ser obtida em animais submetidos a maior exposição a patógenos (Sthaly, 1996).

Coffey \& Cromwell (1995), observando a interação ambiente $\times$ fonte de proteína fornecida, constataram que, em um ambiente considerado limpo (temperatura e a umidade relativa controladas e vazio sanitário prévio de seis meses), houve maior ganho de peso e consumo de ração pelos animais alimentados com dietas contendo leite em pó.

Não houve efeito $(P \geq 0,10)$ dos níveis de plasma na dieta sobre o CRMD dos animais no período 2 (29 a 35 dias de idade). Contudo, observou-se redução de $10,9 \%$ no consumo dos animais alimentados com a dieta com maior nível de plasma em relação ao dos animais da dieta controle, o que indica piora na palatabilidade da dieta. O consumo de plasma pelos animais esteve próximo ao mínimo estabelecido na formulação das dietas. Este resultado difere dos obtidos por Butolo et al. (1999), que verificaram aumento linear significativo no CDR dos animais no período de 0 a 14 dias pós-desmame, ao passo que Kats et al. (1994b), em experimento com leitões desmamados aos $21 \pm 2$ dias de idade alimentados com dietas com níveis crescentes de plasma suíno em pó $(0,0 ; 2,0 ; 4,0 ; 6,0$ e 8,0\%), verificaram efeito quadrático das dietas sobre o CDR e estimaram em $6 \%$ o melhor nível de inclusão de plasma em dietas para leitões recém-desmamados.

Os níveis de plasma influenciaram $(\mathrm{P} \leq 0,05)$ o GPMD, que aumentou de forma quadrática, com melhores resulta- dos no nível estimado de 2,5\% de plasma (Figura 1B). Efeito da inclusão de plasma na dieta sobre o GPMD dos leitões também foi constatado por Rodas et al. (1995), que utilizaram leitões desmamados aos $24 \pm 4$ dias de idade e verificaram maior ganho de peso e consumo de alimento no período de 14 dias após o desmame nos animais alimentados com dietas com $4,0 \%$ de plasma sangüíneo em pó, em comparação àqueles alimentados com 10,0\% de leite em pó e $2,8 \%$ de plasma.

Do mesmo modo, utilizando leitões desmamados aos $12 \pm 1$ dias de idade alimentados com dietas com três níveis de plasma (2,5; 5,0 e 7,5\%), Grinstead et al. (2000) observaram efeito quadrático das dietas sobre o GPMD e concluíram que, para o máximo desempenho no período de 0 a 14 dias pós-desmame, o nível de plasma em dietas para leitões deve ser de $5,0 \%$.

Por outro lado, Kats et al. (1994b) verificaram aumento linear do GPMD com o aumento dos níveis de plasma sangüíneo em pó nas dietas pós-desmame, enquanto Butolo et al. (1999) observaram que o GPMD não foi influenciado pelas dietas.

Angulo \& Cubiló (1998) verificaram maior ganho de peso em animais alimentados com dietas com 6,0\% de plasma em comparação àqueles alimentados com dietas com 3,0\% de inclusão e atribuíram o maior consumo ao nível mais alto de inclusão. Chae et al. (1999) observaram resultados semelhantes, nos animais alimentados com dietas com $6,0 \%$ de inclusão de plasma, o que justifica o melhor desempenho dos animais com o aumento no consumo de ração.

Apesar de a conversão alimentar não ter sido analisada estatisticamente, os melhores resultados, em termos absolutos, foram obtidos nos dois níveis intermediários de inclusão de plasma. Constatou-se melhora de $12,9 \%$ na CA dos animais alimentados com as dietas com 2,8 e 4,2\% de plasma em relação às dietas controle e com 5,6\% de plasma.

Os níveis de plasma não influenciaram $(\mathrm{P} \geq 0,10)$ o CDR dos animais no período 3 . O valor numérico encontrado no nível de 2,0\% de plasma foi, em média, 8,0\% superior em relação ao obtido com a dieta controle.

Entretanto, os níveis de plasma sangüíneo influenciaram ( $\mathrm{P} \leq 0,10)$ o GPMD, que variou de forma quadrática, aumentando até o nível estimado de 1,3\% de inclusão de plasma (Figura 1C).

As baixas respostas à inclusão de plasma sang üíneo em pó sobre o desempenho dos animais a partir do 290 dia de idade podem ser explicadas, em parte, pela maior produção de enzimas endógenas e pelo provável desenvolvimento do sistema imunológico, que, segundo Stein (1996), se completa aproximadamente ao 35 o dia de vida do animal. 
Assim, o animal passa a apresentar maiores condições de utilização dos ingredientes de origem vegetal e o plasma perde gradativamente sua funcionalidade em proporcionar imunidade local no lúmen.

No período 4 (22 a 35 dias pós-desmame), quando os animais consumiram uma dieta única, à base de milho e farelo de soja, não houve efeito $(\mathrm{P} \geq 0,10)$ residual das dietas sobre o CDR e o GPMD. Mesmo não sendo influenciado significativamente pelos níveis de plasma da dieta, o ganho de peso e o consumo de ração dos animais alimentados com as dietas com o maior nível de plasma foram 3,5 e 7,3\% menores que os daqueles alimentados com a dieta controle.

Tem-se relatado que o melhor desempenho de animais alimentados com dietas contendo plasma sangüíneo em pó não se mantém até 28 a 35 dias pós-desmame. Touchette et al. (1996) sugeriram que a perda do efeito benéfico da inclusão do plasma nas dietas sobre o desempenho dos leitões poderia estar relacionada ao crescimento compensatório dos animais alimentados com a dieta controle ou, ainda, à diminuição do consumo com a retirada do plasma da dieta.

Kats et al. (1994b) verificaram que o consumo e a conversão alimentar não foram influenciados significativamente nos 14 dias subseqüentes à retirada do plasma da dieta, contudo, constataram redução no ganho de peso dos animais. Grinstead et al. (2000) relataram que as diferentes fontes protéicas utilizadas nas duas primeiras semanas pós-desmame não influenciaram o GPMD e a CA quando os animais passaram a receber as mesmas dietas à base de milho e farelo de soja. Todavia, esses autores verificaram que o consumo aumentou de forma quadrática, com o ponto de máximo para os animais alimentados com dieta com $2,5 \%$ de plasma sangüíneo.

Hansen et al. (1993) e Kats et al. (1994a) observaram que níveis crescentes de plasma nas primeiras semanas pósdesmame resultaram em decréscimo linear no GPMD no período subseqüente, correspondente à utilização de dietas simples. Nos animais alimentados com dietas contendo plasma, os melhores resultados foram obtidos nas semanas 1 e 2 pós-desmame e os piores, nas semanas 3 e 4 . Os autores sugeriram que esse resultado pode ser justificado pela diferença de palatabilidade entre as dietas com níveis crescentes de plasma e aquelas à base de milho e farelo de soja. Neste trabalho, verificou-se tendência semelhante: os animais alimentados ao longo das semanas experimentais com dietas com níveis intermediários de plasma e que, nas duas primeiras semanas, apresentaram resposta positiva às dietas tiveram redução no consumo e no ganho de peso no período subseqüente, quando fornecida a dieta sem plasma sangüíneo em pó.

\section{Conclusões}

Os níveis de plasma sangüíneo em pó nas dietas de leitões desmamados aos 21 dias de idade são de $4,3 \%$ na primeira semana, $2,5 \%$ na segunda e de $1,3 \%$ na terceira semana pós-desmame.

\section{Literatura Citada}

ANGULO, E.; CUBILÓ, D. Effect of different dietary concentration of spray-dried porcine plasma and a modified soyprotein product on the growth performance of piglets weaned at $6 \mathrm{~kg}$ body weight. Animal Feed Science Technology, v.72, p.71-79, 1998.

BUTOLO, E.A.F.; MIYADA, V.S.; PACKER, I.U. et al. Uso de plasma suíno desidratado por spray dried na dieta de leitões desmamados precocemente. Revista Brasileira de Zootecnia, v.28, n.3, p.326-333, 1999.

CHAE, B.J.; HAN, I.K.; KIM, J.H. et al. Effects of dietary protein sources on ileal digestibility and growth performance for early-weaned pigs. Livestock Production Science, v. 58 , p.45-54, 1999.

COFFEY, R.D.; CROMWELL, G.L. The impact of environment and antimicrobial agents on the growth response of early-weaned pigs to spray-dried porcine plasma. Journal of Animal Science, v.73, n.9, p.2532-2539, 1995.

DEPRÉZ, P.; NOLLET, H.; van DRIESSCHE, E. et al. In: INTERNATIONAL PIGS VETERINARY SOCIETY CONGRESS, 1996, Bolonia. Proceedings... Bolonia: IPVS, 1996. p. 276.

DRITZ, S.S.; TOKACH, M.D.; GOODBAND, R.D. et al. Optimum level of spray dried porcine plasma for early weaned $(10.5 \mathrm{~d}$ of age) starter pigs. Swine day. Kansas State University. 1993.

ERMER, P.M.; MILLER, P.S.; LEWIS, A.J. et al. The preference of weanling pigs for diets containing either skimmed milk or spray-dried porcine plasma. Journal of Animal Science, v.70, p.60, 1992 (suppl. 1).

ERMER, P.M.; MILLER, P.S.; LEWIS, A.J. Diet preference and meal patterns of weanling pigs offered diets containing either spray-dried porcine plasma or dried skim milk. Journal of Animal Science, v.72, p.1548-1554, 1994.

FERREIRA, V.P.A.; FERREIRA, A.S.; DONZELE, J.L. et al. Dietas para leitões em aleitamento e pós-desmame. Revista Brasileira Zootecnia, v.30, n.3, p.753-760, 2001.

GATNAU, R.; CAIN, C.; ARENTSON, R. et al. Spray dried porcine plasma as an alternative ingredient in diets of weanling pigs. Pig News and Information, v. 14, n.4, p.157-159, 1993.

GATNAU, R.; ZIMMERMAN, D.R. Determination of optimum levels of spray dried porcine plasma (SDPP) in diets for weanling pigs. Journal of Animal Science, v.69, p.369, 1991a (suppl.1).

GATNAU, R.; ZIMMERMAN, D.R. Spray dried porcine plasma (SDPP) as a source of protein for weanling pigs in two environments. Journal of Animal Science, v.69, p.103, 1991b (suppl.1).

GOODBAND, R.D.; TOKACH, M.D.; DRITZ, S.A. et al. Practical nutrition for segregated early weaned pig. In: SASKATCHEWAN PORK INDUSTRY SIMPOSIUM, 1995, Saskatoo. Proceedings... Saskatoo: 1995. p.15-22.

GRINSTEAD, G.S.; GOODBAND, R.D.; DRITZ, S.S. Effects of whey protein product and spray-dried animal plasma on growth performance of weanling pigs. Journal of Animal Science, v.78, p.647-657, 2000.

HANSEN, J.A.; NELSSEN, J.L.; GOODBAND, R.D. Evaluation of animal protein supplements in diets of early-weaned pigs. Journal of Animal Science, v.71, p.1853-1862, 1993. 
HARRELL, R.J.; MOON, H.K.; WEAVER, E.M. et al. Effects of animal plasma protein on intestinal recovery of neonatal pigs infected with rotavirus. FASEB Journal, v.14, p.728, 2000.

KATS, L.J.; NELSSEN, J.L.; TOKACH, M.D. et al. The effects of spray-dried blood meal on growth performance of the earlyweaned pig. Journal of Animal Science, v.72, n.11, p.28602869, 1994a.

KATS, L.J.; NELSSEN, J.L.; TOKACH, M.D. et al. The effect of spray-dried porcine plasma on growth performance in the earlyweaned pig. Journal of Animal Science, v.72, n.8, p.20752081, 1994b.

LAWRENCE, K.R.; GOODBAND, R.D.; TOKACH, M.D.S. et al. Comparison of wheat gluten and spray-dried animal plasma in diets for nursery pigs. Journal of Animal Science, v.82, p.3635-3645, 2004.

KATS, L.J.; TOKACH, J.; NELSSEN, J.L. et al. A Combination of spray-dried porcine plasma and spray-dried blood meal optimizes starter pig performance. Iowa State University Swine Research Reports, p.28-30, 2001.

MASCARENHAS, A.G.; FERREIRA, A.S.; DONZELE, J.L. et al. Avaliação de dietas fornecidas dos 14 aos 42 dias de idade sobre o desempenho e a composição de carcaça de leitões. Revista Brasileira de Zootecnia, v.28, n.6, p.1319-1326, 1999.

NATIONAL RESEARCH COUNCIL - NRC. Nutrient requirement of swine. 10.ed. Washington, D.C.: National Academy of Sciences, 1998. 189p.

NOFRARÍAS, M.; MANZANILLA, E.G.; PUJOLS, J. et al. Effects of spray-dried porcine plasma and plant extracts on intestinal morphology and on leukocyte cell subsets of weaned pigs. Journal of Animal Science, v.84, p.2735-2742, 2006.

NOLLET, H.; DEPREZ, P.; van DRIESSCHE, E. et al. Protection of just weaned pigs against infection with $\mathrm{F}^{+} 8^{+}$Escherichia coli by non-imune plasma powder. Veterinary Microbiology, v.65, p.37-45, 1999.

OLIVEIRA, P.A.V.; LIMA, G.J.M.M.; FÁVERO, J.A. et al. Suinocultura: noções básicas. Concórdia: EMBRAPA-CNPSA, 1993. 37p. (Documentos, 31).

OWEN, K.Q.; NELSSEN, J.L.; TOKACH, M.D. et al. Spray-dried egg protein in early weaned strater pig diets. Journal of Animal Science, v.71, p.58, 1993 (suppl. 1)

OWUSU-ASIEDU, A.; BAIDOO, S.K.; NYACHOTI, C.M. et al. Response of early-weaned pigs to spray-dried porcine or animal plasma-based diets supplemented with egg-yolk antibodies against enterotoxigenic Escherichia coli. Journal of Animal Science, v.80, p.2895-2903, 2002

PIERCE, J.L.; CROMWELL, G.L.; LINDEMANN, M.D. et al. Effects of spray-dried animal plasma and immunoglobulins on performance of early weaned pigs. Journal of Animal Science, v.83, p.2876-2885, 2005.
ROSTAGNO, H.S.; ALBINO, L.F.T.; DONZELE, J.L. et al. Composição de alimentos e exigências nutricionais de aves e suínos: tabelas brasileiras. Viçosa, MG: Universidade Federal de Viçosa, 2000. 141p.

RUSSEL, L.E.; WEAVER, E.M. Strategic application of blood proteins in feeding strategies for early weaned pigs and calves. American Association of Swine Practitioners, p.37-45, 1996.

SHURSON, J.; JOHNSTON, L.; PETTIGREW, J. et al. Nutrition and the early weaned pig. Manitoba Swine Seminar, v.9, p.21-32, 1995.

STEIN, H.H. The effects of adding spray dried plasma protein and spray dried blood cells to starter diets for pigs. In: SIMPÓSIO LATINO-AMERICANO DE NUTRIÇÃO DE SUÍNOS E AVES, 1996, Campinas. Anais...Campinas: Colégio Brasileiro de Nutrição Animal, 1996. p.70-86.

STHALY, T. Influencia de la activacion del sistema inmunitario sobre la produtividad y las características nutricionales de dietas para cerdos. In: REBOLLAR, P.G.; MATEOS, G.G.; BLAS, C. (Eds.) Avances en nutricion e alimentación animal. Madri: 1996. 96p.

TEIXEIRA, A.O.; LOPES, D.C.; FERREIRA, A.S. et al. Efeito de dietas simples e complexas sobre a morfo-fisiologia gastrintestinal de leitões até 35 dias de idade. Revista Brasileira Zootecnia, v.32, n.4, p.926-934, 2003.

TORRALLARDONA, D.; CONDE, M.R.; BADIOLA, I. et al. Effect of fishmeal replacement with spray-dried animal plasma and colistin on intestinal structure, intestinal microbiology, and performance of weanling pigs challenged with Escherichia coli K99. Journal of Animal Science, v.81, p.1220-1226, 2003.

TOUCHETTE, K.J.; ALLEE, G.L.; NEWCOMB, M.D. The effects of plasma, lactose, and soil protein sources fed in a phase 1 diet on nursery performance. Journal of Animal Science, v.74, p.170, 1996 (suppl.1).

TOUCHETTE, K.J.; CARROL, J.A.; ALLEE, G.L. et al. Effect of spray-dried plasma and lipopolysaccharide exposure on weaned pigs: I Effects on the immune axis of weaned pigs. Journal of Animal Science, v.80, n.494, p.494-501, 2002.

UNIVERSIDADE FEDERAL DE VIÇOSA - UFV. Manual de utilização do programa do SAEG (Sistemas de Análises Estatísticas e Genéticas). Viçosa, MG: 1997. 150p. 